\title{
The lock-and-key mechanisms of the internal genitalia of the Noctuidae (Lepidoptera): How are they selected for?
}

\author{
KAURI MIKKOLA
}

Finnish Museum of Natural History, P.O. Box 17, FI-00014 University of Helsinki, Finland; e-mail: kauri.mikkola@helsinki.fi

Key words. Apamea, functional anatomy, species-specific, male vesica, female bursa, monandry, polyandry, evolution, genetic drift, sexual selection, zoogeography, Holarctic sister species

\begin{abstract}
In the Noctuidae, the owlet moths, the internal genitalia, i.e. the aedeagus and vesica (penis) in the males, and the bursa copulatrix in the females, together form a lock-and-key mechanism (LKM). The species-specific structures have their counterparts in the opposite sex. The internal LKM constitutes a specific reproductive isolation mechanism (lock-and-key hypothesis), which seem to be the rule in the ditrysian Lepidoptera, and also occurs in the Carabidae (Coleoptera) and some other insects. In contrast, the external genitalia rarely have species-specific counterparts in the sexes. Several results indicate the presence of LKMs: In the Noctuidae, (1) heterospecific differences in the male vesica may prevent sperm transfer or lead to mechanical failure during copulation, (2) the more complicated the specific genitalia structures, the more aberrations may occur even in conspecific copulations, and (3) in many species pairs and groups, and in one large genus, Apamea, the structures in the opposite sexes show a strictly specific correspondence, but, (4) when there is precopulatory isolation due to differences in pheromone production or perception, the internal genitalia may be identical. Conversely, in the Colias butterflies (Pieridae), (5) frequent heterospecific hybridization is associated with the similarity of the internal genitalia. The LKMs seem to protect genomes against alien genes, supposedly selected for because of the lower fitness of specimens with an imprecise LKM and/or inferiority of hybrids. In the literature, the diversity of the noctuid genitalia has been ascribed to sexual selection, because the females were classified as polyandrous. Most species produce the main part of their eggs monandrously, and remate, if at all, in their old age, and are thus successively monandrous and polyandrous. The allopatric divergence in the structure of the internal genitalia of 39 Holarctic pairs of sister species of Noctuidae is suggested to be due to genetic drift. The insecure function of the female pheromones and external genitalia of males are illustrated with the aid of original photographs.
\end{abstract}

1. Introduction

2. Proof of the lock-and-key mechanisms in the internal genitalia

2.1. Anatomical and physiological evidence

2.2. Morphological evidence

2.3. Evidence from other Lepidoptera and other insects

3. Precopulatory mechanical isolation mechanisms

4. Remating in the Noctuidae and other Lepidoptera

5. Divergence among the Holarctic pairs of sister species of Noctuidae

6. Discussion

6.1. General aspects

6.2. Zoogeographical aspects

6.3. Speciation and the species concept

7. References

\section{INTRODUCTION}

The lock-and-key hypothesis (LKH) was defined by Eberhard (1985) and by Shapiro \& Porter (1989) who briefly wrote that it purports "to explain species-specific genital morphology in terms of mechanical reproductive isolation". Eberhard (1985) considers that the lock-andkeys (LKMs) are just "backup or fail-safe devices" and Shapiro \& Porter (1989) think that "the hypothesis has not yet been supported convincingly".

These authors do not specify whether they refer to the external genitalia, the male uncus and valvae, as they are called in Lepidoptera, or to the internal genitalia, the male aedeagus and vesica and female bursa copulatrix, or both (cf. Figs 1-2). The external genitalia are important at an early stage of the coupling process, and the internal genitalia subsequently lock the sexes together rendering the sperm transfer possible. The LKMs occur in the internal genitalia. Compared to the long tradition of using characters of the external genitalia in lepidopteran species taxonomy, the taxonomic use of internal genitalia is a relatively recent and rapidly developing aspect of research (cf. Mikkola, 2007), which has resulted in the evolutionary study of the LKMs.

Most of the authors that discuss insect lock-and-key mechanisms fail to distinguish between the functions of the external and internal genitalia (e.g. Thornhill \& Alcock, 1983; Eberhard, 1985, 1996; Shapiro \& Porter, 1989; Arnqvist, 1998; Arnqvist \& Green, 2002). It is puzzling why these authors do not refer to the pioneering 


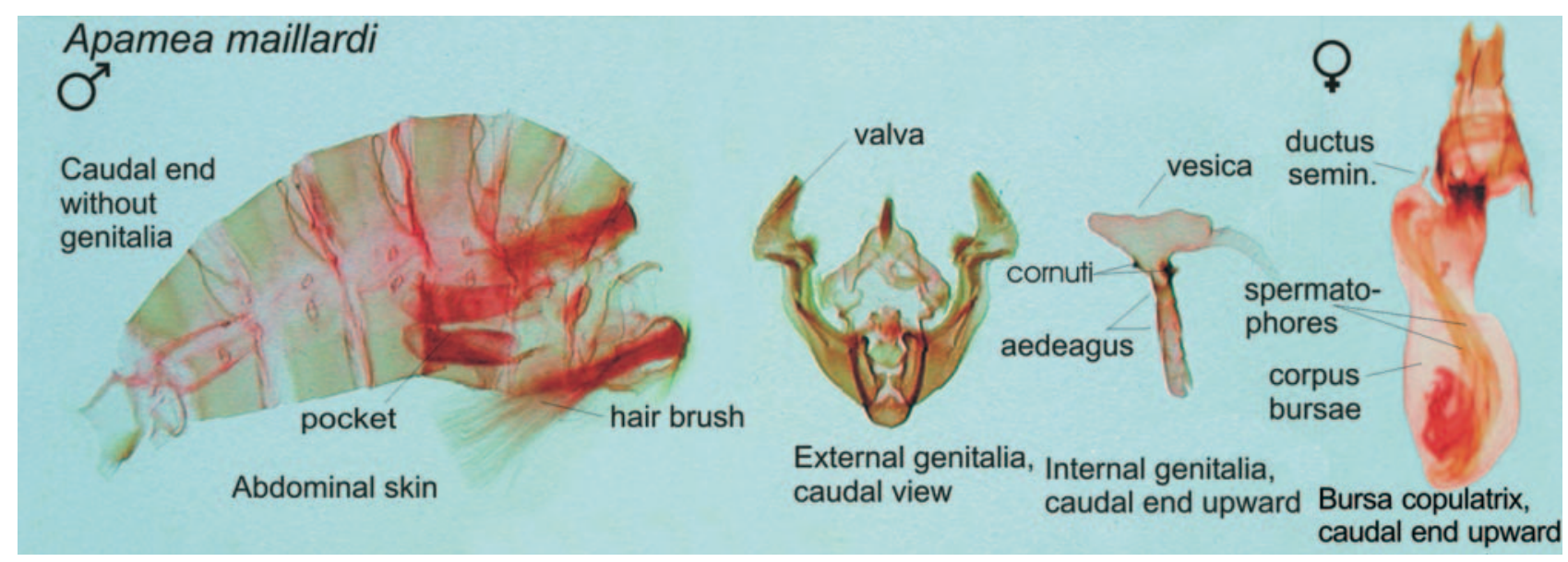

Fig. 1. The male abdominal skin and male and female genitalia of the noctuid moth Apamea maillardi (Geyer, 1834) mounted on microscope slides. From the left: 1 - male skin with hair brushes; 2 - male external genitalia, caudal aspect, opened by pressing, without aedeagus; 3 - male internal genitalia, ventral aspect with posterior upwards; 4 - female genitalia in similar position. The fit of the male internal genitalia into that of the female should be checked by turning them around, cf. Fig. 2 . The overall fit is not selfevident because the receiving parts of the female are often flexible; the correspondence of the shapes of the "shoulders" is easily seen, however. This female has copulated twice as there are two spermatophores in the bursa copulatrix.

work on the functional anatomy of the internal genitalia of Noctuidae (Lepidoptera) by Callahan \& Chapin (1960). However, Eberhard (1985) does cite the number of spermatophores. Similarly, Arnold \& Fischer (1977), publishing in the same journal as Callahan \& Chapin, do not mention their work, nor do Scoble (1995) and Arnqvist \& Nilsson (2000) include it in their reviews. Kristensen (2003) presents illustrations from Callahan \& Chapin (1960), but without mentioning their conclusion about a "definite 'lock-and-key' barrier".

Many examples indicate that LKMs are at present an unpopular topic in discussions of the evolution of genitalia. Some of the traits that were earlier predicted by the LKH, such as negative allometry and little variation in the structure of genitalia (Arnqvist, 1997), were soon, by weak and seemingly ad hoc arguments, attributed to sexual selection (Eberhard et al., 1998, cf. Green, 1999). As regards Lepidoptera, the statement of Hosken \& Stockley (2004) that the LKH is not consistent with the "evidence based on the morphology of the female reproductive tract" and "genital associations during copula", is surprisingly erroneous (see Chapter 2).

Mutanen et al. (2006) and Mutanen \& Kaitala (2006) have unfortunately misunderstood the function of the sclerotized aedeagus (= penis, phallus). The latter authors (2006: 299) exclude it from the internal genitalia by citing Callahan \& Chapin (1960) and claiming that it "is positioned on the female ostium bursae but is not placed in the female ductus bursae", and explaining that the internal genitalia should be soft. However, Callahan \& Chapin (1960: 778) report that in both Peridroma and Pseudaletia the aedeagus is short and "fits only a short distance up the female ductus bursae". For Helicoverpa zea (Boddie), Callahan (1958b: Fig. 6) shows that the aedeagus penetrates the whole length of the ductus bursae. The aedeagus is certainly rigid, because of the requirements of intromission and protection of the membranous vesica (= endophallus). The carina near the tip of the aedeagus and the corresponding fold in the female indicate that during copulation the aedeagus penetrates the entire length of the ductus bursae (cf. Mikkola, 1992: Figs 1 and 3). Only thereafter does the vesica have the space to expand and produce the spermatophore. Note: the short aedeagus of Cyanotricha (Dioptidae) does not enter the female (Miller, 1988).

In describing copulation in Lepidoptera the following nomenclature is followed (cf. Figs 1-2):

(1) External genitalia, the male valvae (referred to as gonopods in many other insect groups) and uncus, grip the female's abdomen at three points at the onset of coupling.

(2) External coupling involves the use of the external genitalia. It is mostly a transient fixing phase before copulation proper, but may have an extended sensory function (see below). It does not have any direct bearing upon reproduction.

(3) Internal genitalia, the male aedeagus and vesica, and female bursa copulatrix from ostium bursae to the opening of the ductus seminalis, show anatomical correspondences (the LKMs). Such a correspondence is often seen also between the male juxta (ventral sclerotization of fultura inferior, the diaphragma) and female lamina antevaginalis of the ductus bursae, as well as between the male spermatophore and female corpus bursae (Lafontaine \& Mikkola, 1987; Mikkola, 1992, see below).

(4) Internal coupling involves the internal genitalia. The LKM lock the sexes together for copulation proper (cf. Callahan, 1958b: Fig. 1), during which the male inserts a spermatophore into the female bursa and sperm transfer may or may not occur.

(5) Postlocking isolation denotes isolation caused by an unsuccessful transfer of sperm into the female ductus seminalis.

(6) Postcopulatory isolation, mainly genetic, occurs after sperm transfer. 


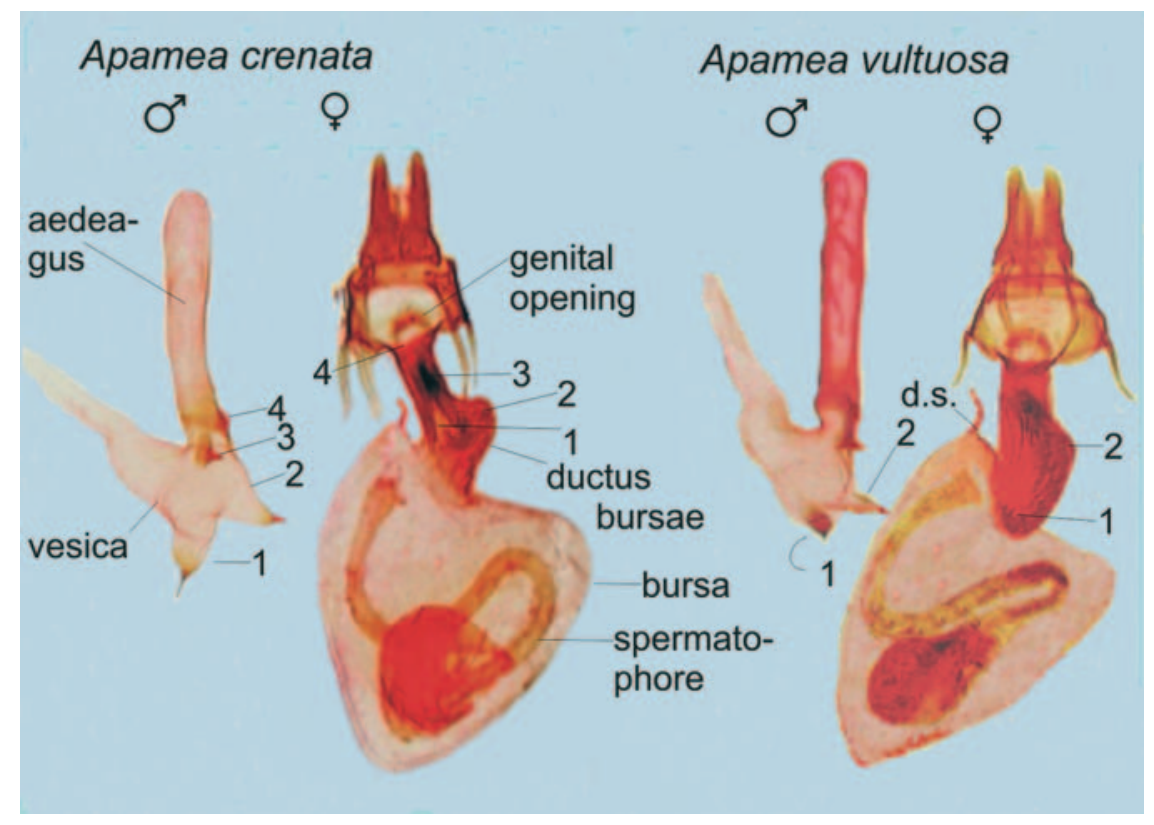

Fig. 2. The lock-and-key mechanism of the palaearctic noctuid species Apamea crenata (Hufnagel, 1766) and its nearctic sister species Apamea vultuosa (Grote, 1875). In both, the aedeagus with vesica is in the position and level reached during copulation. The different orientation of the diverticula of the vesicas is evident (the one projecting cephalad in crenata projects almost dorsad in vultuosa), but the positions of the corresponding pockets in the bursa is more difficult to see: No. 1 is on the ventral wall of the ductus bursae in crenata while it is on the dorsal side in vultuosa. The microscope slides: E. Rockburn, the photographs: R. Talman.

(6) The lock-and-key mechanisms (LKMs) are the morphological correspondences in the structure of the internal genitalia of the two sexes.

(7) The lock-and-key hypothesis (LKH) suggests that the LKMs act as species-specific barriers.

The distinction between "external" and "internal" is appropriate for the copulation of most higher insects (but not the tettigoniids, Orthoptera, see Rentz, 1972). There is presumably a basic difference in the selection acting on the characters of the external as opposed to internal genitalia. The external genitalia usually have no morphological counterparts in the female anatomy (for exceptions, see Chapter 3). The valvae and uncus keep the female abdomen in position and so allow the insertion of the aedeagus into the ostium bursae (e.g. Arnold \& Fischer, 1977; Miller, 1988; Mikkola, 1994). Presumably, the external male organs are subject to sexual selection by the female. The male may rub the female's abdomen with its valvae during internal coupling in the Pieridae (Lorkovic, 1952) and Aglaope infausta (L.) (Zygaenidae; H. Fänger, pers. comm.). Many photographs in the literature indicate that only a sclerotized, partially transparent tube, the male aedeagus, connects a couple in copula, and this is illustrated in a drawing by Callahan (1958b: Fig. 1). The external genitalia have no locking function at this stage.

When a couple is already locked together (i.e. in copula), the success of sperm transfer depends upon whether the male spermatophore will fit into the opening of the female ductus seminalis (Callahan \& Chapin, 1960, Proshold et al., 1975). This isolation mechanism is called postlocking and prezygotic because of possible zygotic, mainly genetic, mechanisms that might become functional later on. In some species of Lepidoptera, mechanical isolation is precopulatory in that external specific structures do not permit heterospecific couplings (see Chapter 3).

The role of LKMs has been discussed for more than one hundred years (for the literature, see, e.g., Mikkola, 1992), but Kullenberg (1947), studying certain Heteroptera, seems to have been the first to mention the locking role of the internal genitalia. In the Tettigoniidae, the species-specific structure of the spermatophore is often the reason why heterospecific copulations do not result in offspring (Rentz, 1972).

The mechanism of copulation in Lepidoptera was first described by Callahan \& Chapin (1960), although Petersen (1904) had earlier described correctly the anatomical correspondence of the shape of the male spermatophore and female bursa copulatrix in the geometrid genus Eupithecia. In noctuid moths, the spermatophores can be resilient or rigid and springlike so that "during mating the process of the insertion can be observed from the insect's exterior"; the cornuti on the vesica wall are equipped with basal muscles that often assist in the insertion of the vesica into the corpus bursae, but in those species where the spermatophore is rigid the vesica may be inserted into the corpus without the aid of muscles (Callahan \& Chapin, 1960).

Fänger \& Naumann (1997) refer to "the mechanical correlation" in the Zygaenidae between the spiny and rough external parts of male and female genitalia as "rather loose", but that between the internal parts "seems much more specific". Lafontaine \& Mikkola (1987) and Mikkola (1992) list the anatomical correspondences in the Noctuidae when male and female internal genitalia couple: (1) the diameter, length and shape of the male 
aedeagus fit those of the female ostium bursae and ductus bursae, (2) the apical part of the aedeagus, often with carina, fits into the distal part of the ductus bursae, which has a receiving fold for the carina, (3) the basal part of the vesica, which turns first out from the aedeagus, often with sclerotized, spiny ridges, fits into the distal part of the ductus bursae and the most proximal part of the bursa copulatrix, with sclerotizations on the bursa wall receiving the ridges on the vesica, and (4) the body of the vesica with its diverticula and cornuti fits into the pockets and sclerotizations of the proximal part of the corpus bursae and the appendix bursae (= cervix b.). (5) The shape of spermatophore fits into the bursa from the most distal (= anterior) part of the corpus bursae all the way back to the appendix bursae and opening of the ductus seminalis. In addition, (6) the male juxta often has extensions that correspond in shape to the caudal margin of the female lamina antevaginalis. How some deciduous spines (cornuti) manoeuvre in the structurally compatible LKMs remains to be shown. Sihvonen (2007) in Table 1 gives a similar list of correspondencies for the geometrid genus Scopula.

In this article, based on published and unpublished data, particularly on Noctuidae (Lepidoptera), information on LKMs and the status of the LKH is reviewed. Older results from studies on Tettigoniidae and more recent ones on Heteroptera, Auchenorrhyncha, Neuroptera, Diptera and Coleoptera are also cited. Some instances of mechanical reciprocal species-specific structures used in external coupling in Lepidoptera are presented. The mating systems of Noctuidae, as regards remating of females, are reviewed. The Holarctic zoogeography is examined in the light of the LKMs of Noctuidae, and the significance of the results for the sexual selection hypothesis and species concept is commented upon. As a supplement, there are photographs from the Tienshan Mountains, illustrating an incident of unexpected function of female pheromones and male external genitalia in two species of microlepidoptera (Figs 4 and $5)$.

\section{PROOF OF THE PRESENCE OF LOCK-AND-KEY MECHANISMS IN THE INTERNAL GENITALIA}

\subsection{Anatomical and physiological evidence}

Direct evidence of the function of internal LKMs is scanty, otherwise articles like this would not be needed.

Many lepidopterists have observed the outcome of heterospecific copulations. In the 1950s I observed a copulation of the noctuids Polia bombycina (Hufnagel) and $P$. trimaculosa (Esper) (= hepatica auct.), collected from sugar baits, which failed as the male $P$. trimaculosa died in copula, and the same happened during mating between Lacanobia thalassina (Hufnagel) and L. suasa (Denis \& Schiffermüller) (J. Kullberg, pers. comm.). There is no doubt this is caused by the incompatibility of the internal genitalia. Actually, even in conspecific copulations the insertion of the spermatophore into the bursa may fail and moths may die (up to $15 \%$, depending on the complexity of genitalia; Callahan \& Chapin, 1960); this is also case in the papilionid butterfly Papilio zelicaon (Sims, 1979: 102).

The function of LKMs is made abundantly clear by the excellent studies of Callahan \& Chapin (1960). By using low temperature to stop copulation at different stages in three noctuid species from different subfamilies, they were able to describe in detail how the male vesica inserts the spermatophore into the female bursa copulatrix so that its opening abuts that of female ductus seminalis. They state in summary that "there exist between them a definite mechanical 'lock-and-key' barrier that prevents crossing". The selection for compatible genitalia must be very strong because even conspecific copulations may end in death.

Hardwick (1965) observed that dissimilar internal genitalia cause problems in heterospecific matings in the noctuid genus Helicoverpa. Lafontaine (1981: 69) indicates that in the genus Euxoa the "combination of vesica shape and bursa shape is critical to positioning of the spermatophore in the bursa". This is due to discharge of the sperm from the spermatophore into the lumen of the bursa instead of into the ductus seminalis (postlocking isolation; Proshold et al., 1975). However, Byers \& Hinks (1978) observed that three species of Euxoa, with slightly different internal genitalia, which never hybridize in the wild, could be induced to produce viable offspring in the laboratory.

Contrary evidence comes from a few cases where precopulatory mechanisms seem to "have taken over". In two pairs of species of Apamea, A. maillardi (Geyer) / A. zeta (Treitschke) and A. scoparia Mikkola, Mustelin \& Lafontaine / A. lateritia (Hufnagel) (Mikkola \& Lafontaine, 1986, Mustelin et al., 2000, respectively), hair brushes are present in the males of the first-mentioned species but absent in the second. The internal genitalia are compatible. The species of the first pair occur sympatrically in many European mountain ranges but those of the latter pair form an allopatric Holarctic pair of sister species.

According to Birch (1970), sexually receptive females of the noctuid Phlogophora meticulosa (L.) do not accept a male whose hair brushes have been amputated. Thus, in the above-mentioned cases involving Apamea, in which an effective precopulatory mechanism is present, no copulatory isolation mechanism develops. Why this should occur in allopatric species is puzzling. Have these two taxa been sympatric in the past? The hair brushes of a freshly emerged male of $A$. scoparia, collected in Wyoming (USA), had a strong smell even to the human nose, somewhere between carrot and vinegar (Mustelin et al., 2000).

There are other cases in which there is a precopulatory isolation mechanism, i.e. difference in the structure of the male antenna, but the internal genitalia are similar. This probably indicates that the female pheromones differ. Thus, in Xestia alpicola (Zetterstedt) (Europe) the antennae of the male are pectinate, in X. albuncula (Eversmann) (Siberia, NW North America) serrate and in $X$. imperita (Hübner) (N North America) filiform (Lafon- 
taine et al., 1998). These taxa would certainly present problems if the two latter species were not sympatric in NW North America.

As in the Xestia alpicola group, most species pairs in the subgenus Orosagrotis of Euxoa differ in antennal serration but not in their genitalia (J.D. Lafontaine, pers. comm.). Some species and infraspecific pheromone types of noctuid species in the genera Euxoa and Feltia in North America may be similar to the above situation. According to J.D. Lafontaine (pers. comm.), the pheromone "types" do not usually mate in the field but in the laboratory may hybridize; often these taxa show differences in antennal structure but hardly any difference in their genitalia.

\subsection{Morphological evidence}

More indirect evidence for LKMs, the strict morphological correspondence in the structure of the genitalia of the sexes, comes mainly from the noctuid genera Apamea, Xestia and Euxoa. It is acknowledged that, in species comparisons, the existence of anatomical correspondence between male and female characters of the internal genitalia does not constitute convincing support for LKH. This support increases, however, as the proportion of species of a group (genus, family) showing them increases. Sometimes experimental data support the LKH (e.g. Rice $\&$ Hostert, 1993).

Nowadays the presence of internal species-specific structures with counterparts in the opposite sex is routinely mentioned in many taxonomical publications on the Noctuidae (e.g. Varga, 1998: 365, Varga \& Guylai, 1999: 171, Mikkola, 1998: 184, Yela, 2002). In exotic Lepidoptera, particularly where there is strong sexual dimorphism, the correspondence between male and female genitalia is often useful in making a taxonomic "marriage", i.e. taxonomically combining the sexes in a single species (J. Holloway, in litt.). The widespread concept of the common presence in Lepidoptera of LKMs is due to new preparation techniques, eversion by injections of the male vesicas and female bursas, which have uncovered a new world of anatomical correspondencies over the past 30-40 years (cf. Mikkola, 2007).

My analysis of the internal genitalia of 50 species of Apamea of the 56 occurring in North America (Mikkola, 1992 ) indicates that there is an average 4.5 lock-and-key characters in each species. Except for the two species pairs cited above, and a few other exceptions, the LKMs are species-specific.

\subsection{Evidence from other Lepidoptera and other insects}

Lepidoptera

In the pierid genus Colias (Pieridae), the roles of the precopulatory isolation mechanisms and LKMs differ from that in the noctuids. In a sample of four species of that genus, $C$. tyche (Böber), $C$. nastes Boisduval, $C$. hecla Lefebvre and $C$. palaeno (L.), and probably many more, the internal genitalia are similar (with extraordinary thin and long aedeagus; KM, unpubl.). In this genus in particular, many hybrids are found (e.g. Lederer, 1941;
Gerould, 1946; Kaisila, 1950; Taylor O.R. Jr., 1972; Priestaf, 1974; Wang \& Porter, 2004). It seems that the precopulatory isolation mechanisms (pheromones, behaviour, phenology, colours including UV-reflectance etc.) are relatively weak, and in the absence of specific differences in the LKMs, hybridisation may occur. The integrity of the genome is perhaps less secure in this genus than in most noctuids.

For the genus Scopula (Geometridae), Sihvonen (2007) notes that "During copulation the sclerotized parts of the internal genitalia...were aligned to each other". Interestingly, Troubridge \& Fitzpatrick (1993) found that the structure of the internal genitalia prevented the fertilisation of eggs in the cross between geometrid (male) Operophtera brumata (L.) $\times($ female) O. bruceata (Hulst) but not in the reverse cross.

Lack of one larval instar in most second generation specimens of the "dimorphic" geometrid moth Selenia tetralunaria (Hufnagel) may cause an aberration in the shape of adult internal genitalia (Mutanen \& Kaitala, 2006). It is noteworthy that the size of internal genitalia is the same in spite of a $20 \%$ size difference in the moths, which supports the LKH.

Naumann (1987) illustrated the anatomy of the genitalia in the genus Zygaena. The anellus (lamina dorsalis) may have a function in opening the female ductus bursae (Fänger \& Naumann, 1997). In this case, parts of the external genitalia may interact with the internal genitalia. In the geometrid genus Eupithecia, the male ventral plate may commonly function to open the colliculum of the ductus bursae of the female (Mikkola, 1994). In another geometrid genus, Selidosema, the sclerotized tip of the male aedeagus seems to be used to open the curved female ductus bursae (Sihvonen \& Mikkola, 2002).

\section{Other insects}

Convincing evidence for the LKH comes from the Coleoptera. Sota \& Kubota (1998) report that in a hybrid zone of two species of Carabus the "genital lock-and-key appears to exert significant selection against hybridization". Males of both species attempt indiscriminately to copulate with heterospecific females, but the result is often death of the female due to rupture of vaginal membranes, and the alien males, also, often damage their own genitalia. The species-specific characters of genitalia are maintained throughout the distribution ranges of these two species, not only in the hybrid zone. Takami (2003) indicated that in a species of Carabus a male genital hook serves to deposit the spermatophore correctly. In a recent study, Usami et al. (2006) showed that in Carabus the species-specific shapes and lengths of genitalia actually lock male and female genitalia together, and that a large difference in the size of genitalia is able to reduce gene flow between sympatric populations.

Sziráki (2002) observed LKMs in the internal genitalia of Neuroptera, Coniopterygidae, because, as in Lepidoptera, they revealed taxonomic associations between sexes. In Diptera, Drosophila, it is not yet understood how the species-specific male internal structures function (Eberhard \& Ramirez, 2004). 
In Heteroptera, in which there is no spermatophore, the male organ has to be long and slender in order to reach the female spermatheca (Bonhag \& Wick, 1953) or it has to pass a valve in the duct corresponding to ductus seminalis (Gschwentner \& Tadler, 2000). Similar close relationships between male filaments and female ducts are reported in the Phlebotominae (Diptera: Psychodidae) by Marcondes \& Alexander (2003). Carr (2005) has recently illustrated, under the title of LKMs, how in an auchenorrhynchan genus the aedeagus interdigitates with the valvulae of the female. Arnqvist \& Rowe (2005; cf. Arnqvist $\&$ Green, 2002) analysed the correlated evolution of secondary sexual traits in water striders (Gerridae).

The compatibility of the precopulatory grasping structures in the two sexes or the length of inserting structures should not be confused with LKMs. In this case, sexual selection by female choice is the best explanation and the structures could be better studied under the title of the mechanical fit hypothesis. Thus, in the genus Lygaeus (Heteroptera), female choice may take place, since the length of the male organ affects the success of the insemination (Tadler, 1999). The situation might be similar in some Auchenorrhyncha (Carr, 2005) and Diptera (Marcondes \& Alexander, 2003). This may be a characteristic of insects that lack spermatophores (cf. Pendergrast, 1956).

\section{PRECOPULATORY MECHANICAL ISOLATION MECHANISMS}

Male insects frequently have complicated external holding devices, but usually the females do not show any corresponding lock-like anatomy (for references, see Thornhill \& Alcock, 1983). Among dayflying species of Lepidoptera quite strange combinations of species have been seen in copula (Reuter, 1880; Wickman, 1985; Wiemers, 1987; Calhoun, 1990; Sudendey, 2003), but probably the internal genitalia are not locked together. In the present supplement it is shown that even two males can become interlocked by their external genitalia (Fig. 5).

Fänger \& Naumann (1997) show that in Zygaena the spiny anellus of the male interplays with the rough surfaces of the female poststernum VIII and sternum IX. According to J. Holloway (in litt.), the interplay of parts on the $8^{\text {th }}$ abdominal sternite is common in exotic noctuoids and geometroids.

There are only a few cases in which the females have parts corresponding with the male valvae in Noctuidae. In Eligma narcissus (Cramer) (Japan), the tips of the valvae form outward directed hooks, which fix the male genitalia into small pockets near the tip of the female abdomen (Ueda \& Saigusa, 1982). In the Bryopolia complex (Varga et al., 1990) and Spaelotis clandestina ssp. suecica (Aurivillius) the male valvae form forks that fit into double depressions at the tip of the female abdomen (for the latter, see a drawing in Mikkola \& Jalas, 1977: 69; during copulation the depressions lose their scales, which provides evidence of their function).
In one American species of Eupithecia, the male has the tips of the ventral plate curved and forceps-like, corresponding to small pouches (the Bolte's pockets) on the female abdomen (Mikkola, 1994). Similarly, in some Californian tettigoniids, the tips of the valvae have species-specific inward hooks which fit into the lateral sclerites of a female of the same species (Rentz, 1972).

\section{REMATING IN THE NOCTUIDAE AND OTHER LEPIDOPTERA}

Arnqvist (1998) indicates that genital divergence would be about twice as great in groups in which females mate more than once (polyandrous) compared to those that only mate once (monandrous). In Lepidoptera, he compares monandrous Psychidae with "polyandrous" Noctuidae, stating that the genitalia of the former are simple in the absence of female choice and those of the latter divergent because of such a choice. The psychids are an ancestral clade of Lepidoptera and the noctuids a derived one, so the result may as well be due to different evolutionary backgrounds as mating differences.

Hosken \& Stockley (2004) consider that "this analysis [Arnqvist, 1998] strongly suggests that sexual selection occurring after intromission has driven insect genital divergence". However, in a large data set of butterflies, Gage et al. (2002) did not find any association between size dimorphism, the degree of polyandry and mating frequency in females, and variance of speciosity, and concluded that sexual selection is not involved.

Arnqvist (1998) reports that 22 species from three genera of Noctuidae are polyandrous: Euxoa 5, Helicoverpa 8 and Heliothis 9 species. Therefore, the mating systems of Noctuidae have been studied more thoroughly.

Callahan (1958a, b) and Callahan \& Chapin (1960) report 41 to $55 \%$ multiple matings (more than one spermatophore in the bursa) of feral females in three species of Noctuidae from different subfamilies, Helicoverpa zea (Heliothinae), Pseudaletia unipuncta (Hadeninae) and Peridroma saucia (Noctuinae). Referring to the conditions of fat body, they noted that in $H$. zea the proportions of rematings were $17.6 \%$ in the youngest class, $42.3 \%$ in the middle-aged class and $48.7 \%$ in the oldest class, and in P. unipuncta $8.3 \%, 27.3 \%$ and $65.7 \%$, respectively. In $P$. saucia the numbers were similar but too low for comparison. A third of females did not remate at all. Before remating most females laid at least 500 to 1000 eggs.

Svärd \& McNeil (1994) observed that in Pseudaletia unipuncta 940 to 1384 eggs were oviposited before the second mating. In the laboratory, Heliothis zea mated only once, which indicates that the females laid an average of $798 \mathrm{eggs} /$ spermatophore (Callahan, 1958a). In the sister species of $H$. zea, $H$. armigera, single-mated females laid around the same number of eggs as $H$. zea, $876 \pm 223$, while those that mated two to three times laid ca. 1070 eggs (Hou \& Sheng, 1999).

In $H$. armigera, $88 \%$ of mated females had only one spermatophore, and the rest two (Jallow \& Zalucki, 1998). The frequency of remating, based on field collected specimens, was $43 \%$ in the genus Apamea 
(Mikkola 1992), and 54.8\% for Spodoptera littoralis (Boisduval) (Sadek, 2001) (both Amphipyrinae). Svensson et al. (1998) report a lower value, 34\%, of rematings for Agrotis segetum (Denis \& Schiffermüller) (Noctuinae); the singly mated females laid 590 eggs and the remated ones 670 .

According to the above, the females can lay at least $3 / 4$ of their eggs when fertilized by a single male. Thus, they behave mainly monandrously. Really polyandrous species (see below) should be analysed for the effects of sexual selection.

Svensson et al. (1998) describe the lack of female selection in Agrotis segetum: all females found by a male always mated with the first one that entered the cage and encountered and courted her. "None of the females showed any rejection toward encountering males". According to these authors, "a female does not have to remate to be able to fertilize and oviposit her entire egg load". They suppose that selection of a good mate is less important than remaining unmated and/or exposed to predation and parasitoids.

In the polyandrous noctuid moth, Spodoptera frugiperda (J.E. Smith), the females mate an average of 3.7 times, and two matings commonly occur in a single night (Simmons \& Marti, 1992). Polyandry is an heritable trait in the closely related $S$. exigua (Hübner) (Torres-Vila et al., 2001). In an arctiid moth, in which the spermatophores contain defensive substances as a nuptial gift, Utetheisa ornatrix (L.), females may contain up to thirteen spermatophores (Lamunyon, 1997).

In the butterflies, monandry and polyandry may occur as ecological strategies in a family, Pieridae (Forsberg \& Wiklund, 1989; Wiklund et al., 2001), in congeneric species, Nymphalis io (L.) and N. c-album (L.), respectively (Wiklund et al., 2003; the nomenclature modernized), and even within a species, Pieris napi (L.) (Wedell et al., 2002; Välimäki \& Kaitala, 2007). Nearly $90 \%$ of the females of the nymphalid butterfly Hypolimnas bolina (L.) have only one spermatophore (Kemp, 2001), and in mated Melitaea cinxia (Linnaeus) that percentage is 92 to 93.5 (Kuussaari, 1998).

In a microlepidopteran, the gelechiid Phthorimaea operculella (Zeller), half of the moths mate once and the rest twice or three times (Makee \& Saour, 2001). The females of the pyralids Chilo suppressalis (Walker) and Diatraea considerata Heinrich (Jiao et al., 2006; OsorioOsorio \& Cibrián-Tovar, 2000, respectively) usually mate once, but in Plodia interpunctella (Hübner) the mated females have an average of 2.2 spermatophores (Huang \& Subramanyam, 2003).

As repeatedly mentioned in the literature, additional copulations supposedly take place because of shortage of sperm or nutrients, and Arnqvist \& Nilsson (2000) consider, as do several other authors, that female fitness increases with multiple mating. The results of Svensson et al. (1998) and Hou \& Sheng (1999) indicate that increased oviposition is due to acquisition of nutrients during further matings. Wiklund et al. (2001) note for butterflies that "the positive effect of male nutrient contribution is substantial" (cf. Vahed, 1998).

Arnqvist \& Nilsson (2000) did not account for the temporal sequence of multiple matings. Thus, in Arnqvist's "polyandrous" noctuids the most common number of spermatophores is one, and the additional spermatophores, if any, fertilize roughly one quarter of the eggs. The examples above, as well as the results from a different standpoint of Gage et al. (2002), indicate that sexual selection has a little if any role in the diversification of lepidopteran genitalia.

\section{DIVERGENCE AMONG THE HOLARCTIC PAIRS OF SISTER SPECIES OF NOCTUIDAE}

Speciation processes in insects can be best studied in the faunas that have become isolated by a series of geological events. This is the case in the Holarctic where the fauna was affected by the disruption of the forest and land connections caused by climate changes during Pliocene to Holocene. The term "holarctic" means in this treatment "occurring on both sides of the Bering Strait".

The common problem in continental comparisons is the paucity of comparative taxonomical synopses of large terrestrial taxa. The Noctuidae seems to be the only large insect family, with some 5000 temperate to arctic species in the Holarctic, in which the Holarctic relationships have been analysed by balanced sampling from both sides of Beringia and utilizing high-resolution taxonomical tools (LKMs; cf. Sanmartín, 2001). The overviews of Lafontaine \& Wood (1988) and Mikkola et al. (1991), more specific publications (e.g. Lafontaine \& Mikkola 2003) and unpublished data have created an opportunity to analyse the process of speciation in two regions, i.e. the Palaearctic and Nearctic.

The populations of arctic species on both sides of the Bering Strait were recently in contact with each other, that is, around 13 thousand years ago, and are mostly taxonomically homogeneous (Lafontaine \& Wood, 1988; Mikkola et al., 1991). However, the forest contact between the Palaearctic and Nearctic became discontinuous in the late Pliocene, around 3.5 myr ago (Sanmartín et al., 2001). The consequence was that most species of the arboreal (forest belt) on both sides of the Bering Strait diverged at the species level. The neighbouring continents now form a great playground for the events of vicariance.

By excluding the noctuid species introduced by man and some cosmopolitan species and long-range migrants, 117 originally Holarctic contacts were found. Of these, 75 are species with Holarctic distribution, i.e. they are taxonomically homogeneous west and east of the Bering Strait; most of them are arctic or subarctic species. In 42 $(36.9 \%)$ additional taxa there are signs of divergence and they are regarded as sister species because, in spite of general similarity of habitus and morphology, their internal genitalia are incompatible. Of these 42, 37 $(88.1 \%)$ are species of the arboreal, namely 32 temperate and 5 boreal species; the rest (5) are species of steppe and mountaineous habitats. The relative role in this group of 
differentiation in their outer appearance (habitus) and external and internal genitalia was estimated for 39 species (data for the rest are missing; Tables 1 and 2).

One could argue that there is a danger of circular reasoning in this treatment, i.e. the results are dependent on the method chosen. This is unlikely, however, because the whole spectrum of taxa showing Holarctic relationships from congenerics through species pairs to identical taxa was revised. After judging between possible differences in the habitus or external genitalia, or often without any such hints, the internal genitalia were examined. For the latter, if both sexes show the same functional difference compared to the pair of the neighbouring continent, the pairs belong to different species. In the rare cases where such differences are absent, but there is, for instance, a difference in external genitalia, a more subjective judgement on the differentiation of the gene pools had to be made. Thus, the different types of distinguishing characters have similar possibilities for demonstrating species borders.

TABLE 1. The distinguishing characters of the Holarctic pairs of sister species: $\mathrm{h}$ - habitus, e - external genitalia, $\mathrm{i}$ - internal genitalia. The decision about the quality of the differences was made by a neutral researcher, J.D. Lafontaine, Ottawa.

\begin{tabular}{ccccccccc}
\hline Total & hei & h & he & e & hi & ei & i & none \\
\hline 39 & 14 & - & 1 & 3 & 2 & 8 & 10 & $1^{*}$ \\
\hline
\end{tabular}

*Apamea lateritia/scoparia where the difference is in the male hair brushes.

TABLE 2. Occurrence and percentages of distinguishing characters in 39 Holarctic pairs of sister species.

\begin{tabular}{cccc}
\hline All char. & habitus & external genitalia & internal genitalia \\
\hline $14(35.9 \%)$ & $17(43.0 \%)$ & $26(66.7 \%)$ & $34(87.2 \%)$ \\
\hline
\end{tabular}

The distributions of distinguishing characters were compared (1) with all pairs of sister species included, and (2) for the supposedly most recent speciations where differentiation is not visible in all characters. The distribution of characters in the total material $(17 / 26 / 34)$ is not significantly different from an even distribution $(\mathrm{df}=2$, $\chi^{2}=2.93, \mathrm{p}<0.231$ ). If the 14 species pairs in which all the characters differ, supposedly representing the oldest divergences, are omitted, then in the remaining 25 species pairs habitus occurs 3 times, external genitalia 12 and internal genitalia 20 times, and the distribution is uneven $\left(\mathrm{df}=2, \chi^{2}=7.32, \mathrm{p}<0.026\right)$.

Thus, habitus characters do not usually occur independently of genitalia characters. Internal genitalia most often constitute a distinguishing character on their own, and almost equally often in combination with external genitalia.

\section{DISCUSSION}

\subsection{General aspects}

Most species of Noctuidae investigated, as well as many other lepidopteran species, are genetically isolated from their relatives by virtue of internal, mechanical sys- tems, LKMs, and the same seems to be true at least for many other Lepidopterans and for some Coleopterans. The lack of an internal isolating mechanism in a few cases where there is a precopulatory isolating mechanism, such as male hair brushes (see above), supports this rule.

It could be expected that the more closely related the species are, the more similar the LKMs would be, as is, for instance, the general shape of the male valva. However, in Noctuidae the internal genitalia are usually different, no matter how closely related the species. This constitutes evidence for species-specific LKMs.

There is very limited intrapopulation or geographical variation in the internal genitalia. Thus, no transcontinental clines were found. This differs from the external genitalia, in which the geographical variation has been demonstrated many times.

In most cases the LKMs seem to reinforce the results of the precopulatory isolation mechanisms (phenology, behaviour, pheromones, mechanical devices etc.; cf. Eberhard, 1985). The LKMs supposedly prevent any genetic hazards that might result from the introgression of alien genetic material. The mechanism has presumably evolved through the lower fitness of hybrids or mutants, because of the less perfect compatibility of their genitalia. The protection of the integrity of the genome by LKMs has great evolutionary significance and is considered to be the ultimate cause of the evolution of LKMs.

The strong species-specifity of the internal genitalia could be taken as evidence for the mechanical fit hypothesis. However, in this case the male organs should show variation that permits sexual selection by the female. But the locks and keys fit each other and show little variation; any deviations are supposedly selected against.

When the conspecific sexes are internally coupled, it is probably too late for the female to abandon the male, or prevent insemination (cf. Sims, 1979; Svensson et al., 1998). Information in the literature (Callahan \& Chapin, 1960 , and others) indicates that the first spermatophore is enough for a considerable part of a noctuid female's lifespan (Chapter 4). In this paper, only the external genitalia of Lepidoptera are considered to be subject to sexual selection. That in the Holarctic the external genitalia diverge less than the internal genitalia (Chapter 5) is further proof against sexual selection acting on allopatric species. The negatively allometric growth and small amount of variation in genitalia (see Ohno et al., 2003; Mutanen et al., 2006; Mutanen \& Kaitala, 2006) also do not conform with cryptic female choice proposed by Eberhard (1996). I fully agree with Arnqvist (1997) that negative allometry is what is expected from LKMs.

The recurrent controversy regarding the presence, or not, of LKMs seems to be largely unnecessary (cf. Edwards, 1993). The relative importance of the precopulatory isolation mechanisms and LKMs varies widely among insect groups. Therefore, it may be impossible to develop a universal explanation for the evolution of genitalia. In Noctuidae, LKMs are particularly widespread and important, while in several species of Colias butter- 
flies LKMs are similar and the precopulatory mechanisms seem to be more important.

In the literature, the apparent more complex structure of male genitalia is frequently cited as evidence against the lock-and-key hypothesis (e.g. Eberhard, 1985; Arnqvist, 1998). However, this is true only for external genitalia, which in this article are also considered to have evolved under sexual selection. In the internal genitalia, sclerotization of structures in males may also be more conspicuous than those in females, but as the sexes show a corresponding order of morphological details, the question about the complexity is a matter of opinion. This difference between external and internal genitalia provides evidence for LKMs in the internal but not external genitalia. Arnqvist (1997) listed the predictions of three hypotheses of genital evolution, the LKM, pleiotropism and sexual selection. Pleiotropism is unlikely to have been a factor in the evolution of species in the Holarctic history because usually only the internal component of genitalia evolves (Chapter 5), and the possibility for sexual selection is negligible (Chapter 4).

\subsection{Zoogeographical aspects}

Holarctic zoogeography is not an anomaly or exception. It provides a large-scale laboratory experiment (cf. Rice \& Hostert, 1993), showing what happens when a continental fauna of huge extent is cut in two. From the present, a momentary point on the evolutionary continuum, the history of the fauna can be traced back to past geological eras.

The characters of internal genitalia of the species studied were unexpectedly constant. No greater geographical variation could be found on the continental scale than within local populations, and the latter is rather small. The large homogeneous continental populations with abrupt termination when populations are isolated, and the recurrent nature of this pattern, show that the phenomenon is real and not dependent on the choice of species.

In the case of sister species, four pairs (males and females) of specimens repeatedly revealed these relationships over the whole Holarctic: for instance, if we take a male and female from Britain and a second pair from Japan, the genitalia are the same. A third pair, chosen from Alaska, i.e. behind the Bering Strait, has clearly different genitalia, and a fourth pair, from Labrador, resembles those from Alaska (cf., e.g., Lafontaine \& Mikkola, 2003). In some species different patterns are recorded: in a few species pairs the border is in Western Siberia where there has been a waterway for thousands of years, the Turan Strait.

The stability of LKMs on a continental scale indicates that the characters must be controlled by transcontinental gene flows. Supposedly a very weak flow is sufficient to control the structure of genitalia. Therefore, any level of hybridisation would be detrimental for the integrity of the genome ("selection against hybrids must have been remarkably widespread and severe", Edwards, 1993).

In Noctuidae and Geometridae, hybridization hardly ever occurs, and this might be due to strict LKMs. Only in certain groups, such as the genus Amphipoea among noctuids and the geometrid genera around Lycia (Ennominae) does some hybridisation occur (cf. Colias above).

\subsection{Speciation and the species concept}

Rice \& Hostert (1993) acknowledged that we don't have "time machines" to examine "the relative importance of various speciation mechanisms". Holarctic zoogeography offers, however, some possibilities of tracing the evolution. The huge distribution areas of numerous lepidopteran species in the Holarctic arboreal were divided into separate Palaearctic and Nearctic areas. Thus, there were no sampling drift or bottlenecks, as the sister populations became fully allopatric. Pleiotropy and genetic hitchhiking as speciation forces are unlikely as mainly the internal genitalia diverged (Tables 1 and 2). It has already been noted that sexual selection is anatomically unlikely in the Noctuidae, and that in one wellstudied species, Agrotis segetum, the females always accept the first male (Svensson et al., 1998; Chapter 4). Moreover, the organs that should be under sexual selection, the external genitalia, diverge less rapidly than the internal genitalia (Chapter 5). The generally quick diversification of the internal genitalia, on an evolutionary scale, noted also by Mutanen et al. (2006), is remarkable because the male and female organs must evolve together and are thus subject to stabilizing selection. Also for butterflies, Gage et al. (2002) concluded that "speciation occurs independently of sexual selection".

Why then do the internal genitalia diverge allopatrically? The only feasible explanation is random genetic drift, once the Holarctic gene flow stopped. The sister species have the same genetic background, but despite that they diverged. Such a continuous divergence is probably a plesiomorphic feature, common to most or all insects, which possibly evolved because of the inferiority of hybrids. Thus, it has probably arisen in the distant past in connection with the radiation of insects. Song et al. (2006) have shown that geographic differentiation is often underestimated. Nonetheless, in Noctuidae, speciation was much slower than in the Enallagma damselflies (Odonata) in the northern Holarctic caused by climate fluctuations in the Quaternary (Turgeon et al., 2005).

The "biological species concept" developed by Mayr (1963) supposes, among other phenomena, that the isolation mechanisms are strongly reinforced when the species live sympatrically [character displacement; cf. Kawano (2004) for Coleoptera]. The results for Apamea and other noctuid genera do not support this concept:

(1) Among the North American species of Apamea, those with close relatives have, on average, the same number of lock-and-key characters as those without such relatives (4.4/4.7, respectively; Mikkola, 1992). Thus, no character displacement has occurred.

(2) When the arboreal of the Holarctic was split in two, the LKMs of many lepidopteran populations diverged. Why should this have occurred, when the sister species was "safely beyond the sea"? 
A

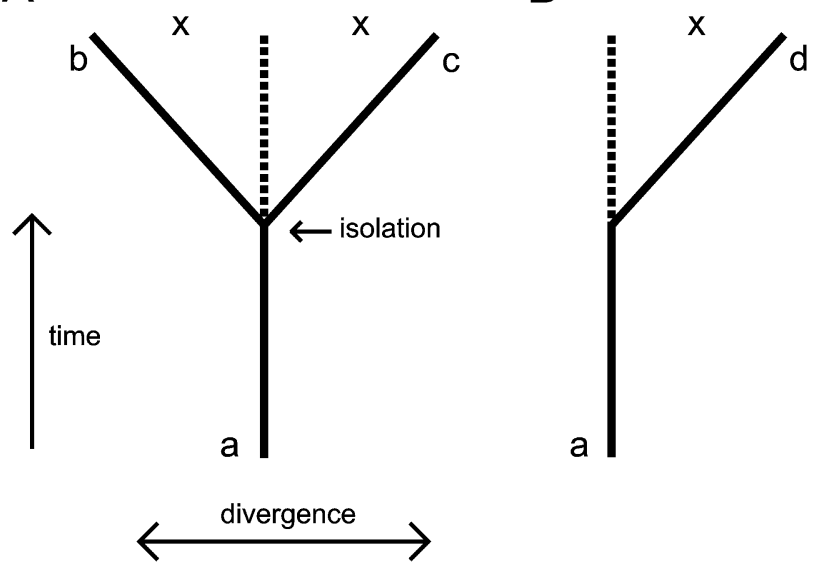

Fig. 3. Schematic divergence of continental populations of Noctuidae from the ancestral population, presuming symmetric differentiation and differentiation in a hypothetical species. A two sister species, based on the taxonomic material presented in Tables 1 and 2; B - the evolution of a species without a sister species over the same time scale as on $\mathrm{A}$.

It seems that the on-going divergence is driven by a force that cannot be accounted for by the biological species concept. Sota \& Kubota (1998) present a similar zoogeographic view of the carabids: the species diverged allopatrically. Secondarily, they spread together, with the result that hybridisation was unsuccessful. Thornhill \& Alcock (1983: 413) noted, in the context of speciesspecific courtship behaviour, that allopatric divergence is an "incidental by-product" which "may have nothing whatever to do with the avoidance of hybridisation".
They (1983: 409) did not find evidence of a different rate of divergence in the courtship behaviour in sympatric and allopatric species.

In contrast to the internal genitalia, the ecological niche seems to remain the same on the two continents. Based on experience, the species guild, protective colouration, larval host plants etc. seem to stay roughly the same. Thus, the selection for the ecological status quo is strong.

Researchers who have considered the biological species concept to be unsatisfactory have developed new alternatives (cf. Mikkola, 1993). Paterson's (1985) “recognition concept" implies that precopulatory mechanisms would result in correct species pairing. Particularly in diurnal Lepidoptera this is often the case, but in Noctuidae, the solution is usually the compatibility of internal genitalia, with less likelihood of isolation due to precopulatory events.

Templeton's (1989) "cohesion concept" fits the available data best. The "cohesion" is kept secure by the LKMs, since the sexes must drift pairwise away from other pairs of sexes. Organisms that do not conform to the opposite sex must be strongly selected against. Thus, cohesion species of Lepidoptera can be defined as "multidimensional entities with tight cohesion in all directions, differing from all other entities. They are most inclusive populations of these biparental organisms which share compatible LKMs, or sometimes compatible precopulatory recognition mechanisms" (cf. Mikkola, 1993).

The interesting ultimate question is why the structures of the genitalia drift apart even under allopatry. This seems to be a basic characteristic of internal, and less so of external, genitalia. Because this divergence takes place
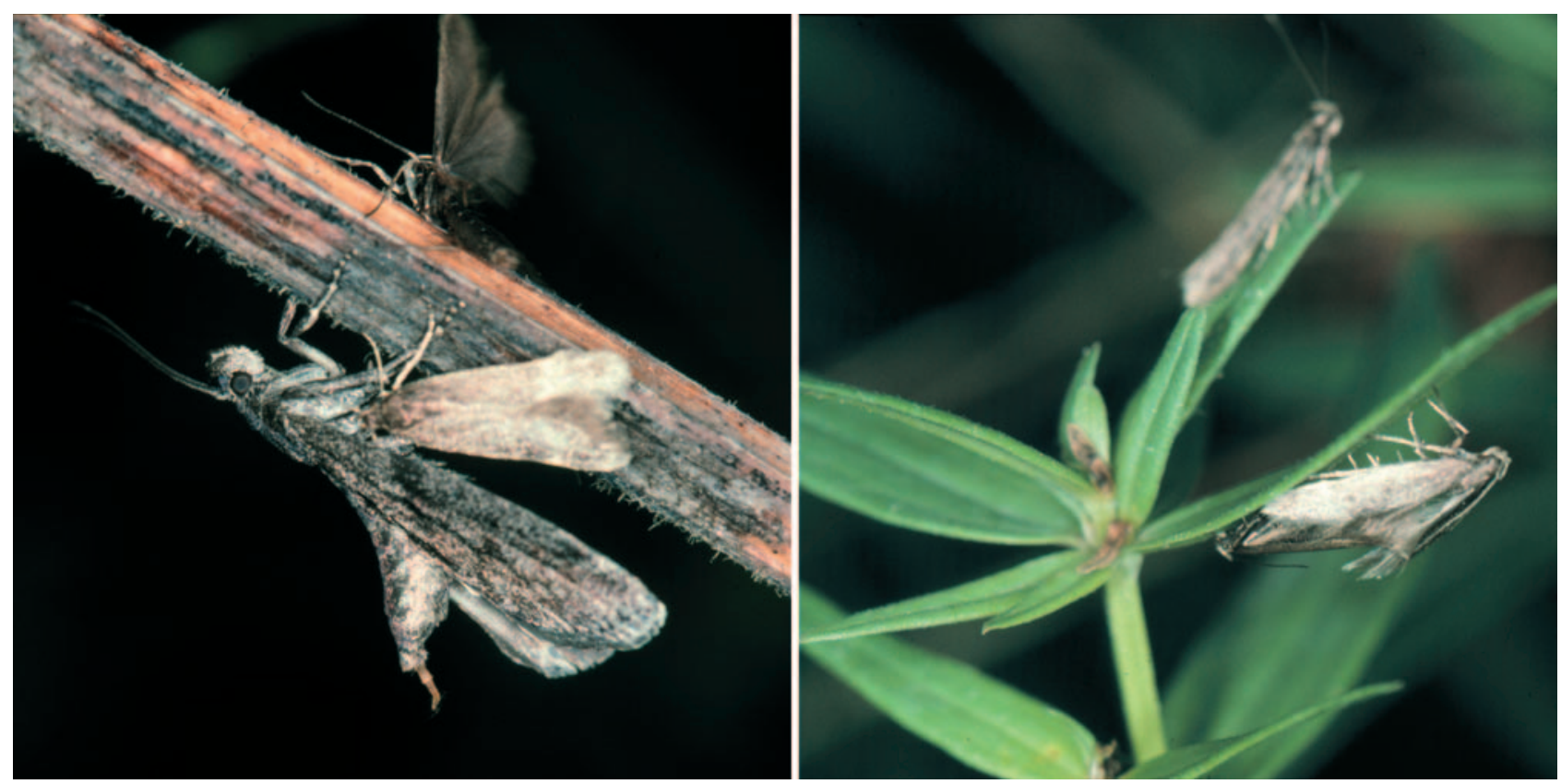

Figs 4 and 5. Examples of insecure function of the pheromones and of the external genitalia. Left: In the Tianshan Mts., Kazakhstan, at an elevation of $2700 \mathrm{~m}$, a female of Pyla fusca (Haworth) (Pyralidae) is calling, but the result is a cloud of males of Bryotropha phycitiniphila (Karsholt \& Rutten, 2005) (Gelechiidae). Right: After a while, two males copulate, evidently by external coupling. This is rare documentation of homosexuality among moths. These copulating males are preserved in the Finnish Museum of Natural History, Helsinki. Photographs: K. Mikkola. 
in allopatric sister species, similar evolutionary change probably takes place in all other species, irrespective of their relations to other taxa (Fig. 3). Hence the phenomenon of the high diversity in insect genitalia, which has generated so much perplexity in the literature.

ACKNOWLEDGEMENTS. J.D. Lafontaine (Ottawa) is acknowledged for long-lasting and fruitful cooperation, for the microscopic slides used in preparing the illustrations in this paper, for rating the taxonomical differences of the Holarctic sister species and for invaluable comments on an earlier version of the manuscript. Great thanks are due to J.D. Holloway (London) for valuable comments on the manuscript as well as for his own observations, to M. Mutanen and P. Välimäki (Oulu) and to M. Rantala (Turku) for commenting on the manuscript and for advice about literature, to J. Sorvari (Turku) for statistical assistance, to H. Fänger (Bonn) for discussions about the copulatory mechanisms in Zygaena, and to an anonymous language reviser. Funding for this study was received from the Academy of Finland and from the University of Helsinki.

\section{REFERENCES}

Arnold R.A. \& Fischer R.L. 1977: Operational mechanisms of copulation and oviposition in Speyeria (Lepidoptera, Nymphalidae). Ann. Entomol. Soc. Am. 70: 455-468.

ARNQvist G. 1997: The evolution of animal genitalia: distinguishing between hypotheses by single species studies. Biol. J. Linn. Soc. 60: 365-379.

ARNQVIST G. 1998: Comparative evidence for the evolution of genitalia by sexual selection. Nature 393: 784-786.

ARnQvist G. \& Green L. 2002: Correlated evolution of male and female morphologies in water striders. Evolution 56: 936-947.

Arnqvist G. \& NiLsson T. 2000: The evolution of polyandry: multiple mating and female fitness in insects. Anim. Behav. 60: $145-164$.

ARNQVist G. \& Rowe L. 1995: Sexual conflict and arms races between the sexes: a morphological adaptation for control of mating in a female insect. Proc. R. Soc. Lond. (B) 261: 123-127.

BIRCH M.C. 1970: Pre-courtship use of the abdominal brushes by the nocturnal moth Phlogophora meticulosa (L.) (Lepidoptera, Noctuidae). Anim. Behav. 18: 310-316.

Bonhag P.F. \& Wick J.R. 1953: The functional anatomy of the male and female reproductive systems of the milkweed bug, Oncopeltus fasciatus (Dallas) (Heteroptera: Lygaeidae). $J$. Morphol. 93: 177-230 + xxiv.

BYERS J.R. \& HINKS C.F. 1978: Biosystematics of the genus Euxoa. XI. Mating discrimination between three closely related species of the declarata group. Can. J. Zool. 56: 1981-1987.

Calhoun J.V. 1990: Natural intergeneric mating in Lycaenidae. J. Lepidopt. Soc. 44: 95-96.

Callahan P.S. 1958a: Behavior of the imago of the corn earworm, Heliothis zea (Boddie), with special reference to emergence and reproduction. Ann. Entomol. Soc. Am. 51: 271-283.

Callahan P.S. 1958b: Serial morphology as a technique for determination of reproductive patterns in the corn earworm, Heliothis zea (Boddie). Ann. Entomol. Soc. Am. 51: 413-428.

Callahan P.S. \& Chapin J.B. 1960: Morphology of the reproductive system and mating in two representative members of the family Noctuidae, Pseudaletia unipuncta and Peridroma margaritosa, with comparison to Heliothis zea. Ann. Entomol. Soc. Am. 53: 763-782.
CARR S.M. 2005: Lock-and-key genitalia in insects. http://www. mun.ca/biology/scarr/Lock-and-Key.htm

Eberhard W.G. 1985: Sexual Selection and Animal Genitalia. Harvard University Press. Cambridge, Mass, 244 pp.

Eberhard W.G. 1996: Female Control. Sexual Selection by Cryptic Female Choice. Monographs in Behavior and Ecology. Princeton Univ. Press, Princeton, New Jersey, 501 pp.

EBERHARD W.G. \& Ramirez N. 2004: Functional morphology of the male genitalia of four species of Drosophila: failure to confirm both lock and key and male-female conflict predictions. Ann. Entomol. Soc. Am. 97: 1007-1017.

Eberhard W.G., Huber B.A., Rodriguez R.L., Briceño S.R.D., Salas I. \& Rodriguez V. 1998: One size fits all? Relationships between the size and degree of variation in genitalia and other body parts in twenty species of insects and spiders. Evolution 52: 415-431.

EDWARDS R. 1993: Entomological and mammalogical perspectives on genital differentiation. TREE 8: 406-409.

FÄNGer H. \& NAUMANN C.M. 1997: Genital morphology and copulatory mechanism in Zygaena trifolii (Esper, 1783) (Insecta, Lepidoptera, Zygaenidae). Acta Zool. 79: 9-24.

ForsBerg J. \& WiKLUND C. 1989: Mating in the afternoon: timesaving in courtship and remating by females of a polyandrous butterfly Pieris napi. Behav. Ecol. Sociobiol. 25: 349-356.

Gage M.J.G., Parker G.A., Nylin S. \& Wiklund C. 2002: Sexual selection and speciation in mammals, butterflies and spiders. Proc. R. Soc. Lond. (B) 269: 2309-2316.

Gerould J.H. 1946: Hybridization and female albinism in Colias philodice and eurytheme. A New Hampshire survey in 1943 with subsequent data. Ann. Entomol. Soc. Am. 39: 383-396.

GREen A.J. 1999: Allometry of genitalia in insects and spiders: one size does not fit all. Evolution 53: 1621-1624.

Gschwentner R. \& TAdLer A. 2000: Functional anatomy of the spermatheca and its duct in the seed bug Lygaeus simulans (Heteroptera: Lygaeidae). Eur. J. Entomol. 97: 305-312.

Hardwick D.F. 1965: The corn earworm complex. Mem. Entomol. Soc. Can. 40: 1-247.

Hosken D.J. \& Stockley P. 2004: Sexual selection and genital evolution. Trends Ecol. Evol. 19: 87-93.

Hou M. \& Sheng C. 1999: Fecundity and longevity of Helicoverpa armigera (Lepidoptera: Noctuidae): effects of multiple mating. J. Econ. Entomol. 92: 569-573.

Huang F. \& Subramanyam B. 2003: Effects of delayed mating on reproductive performance of Plodia interpunctella (Hübner) (Lepidoptera, Pyralidae). J. Stored Prod. Res. 39: 53-63.

JALLOW M.F.A. \& ZALUCKI M.P. 1998: Effects of egg load on the host selection behaviour of Helicoverpa armigera (Hübner) (Lepidoptera: Noctuidae). Austr. J. Zool. 46: 291-299.

JiAO X., XUAN W. \& Sheng C. 2006: Effects of delayed mating and male mating history on longevity and reproductive performance of the rice stem borer, Chilo suppressalis (Walker) (Lep., Pyralidae). J. Appl. Entomol. 130: 108-112.

KaIsILA J. 1950: Über die vermuteten Bastarde zwischen Colias hecla sulitelma Aur. und C. nastes werdandi Zett. (Lep., Pieridae). Ann. Entomol. Fenn. 16: 112-121.

Kawano K. 2004. Developmental stability and adaptive variability of male genitalia in sexually dimorphic beetles. Am. Nat. 163: 1-15.

KemP D.J. 2001: The ecology of female receptivity in the territorial butterfly Hypolimnas bolina (L.) (Nymphalidae): implications for mate location by males. Austr. J. Zool. 49: 203-211. 
KRISTENSEN N.P. 2003: Reproductive organs. In: Lepidoptera, Moths and Butterflies. Vol. 2. Handbuch der Zoologie IV/36. Walter de Gruyter, Berlin, pp. 427-447.

KullenBerg B. 1947: Der Kopulationsapparat der Insekten aus phylogenetischem Gesichtspunkt. Zool. Bidrag från Uppsala 147: 79-90.

KUUSSAARI M. 1998: Biology of the Glanville Fritillary Butterfly (Melitaea cinxia). PhD thesis, Department of Ecology and Systematics, University of Helsinki.

LAFONTAINE J.D. 1981: Classification and phylogeny of the Euxoa detersa group (Lepidoptera, Noctuidae). Quaest. Entomol. 17: 1-120.

Lafontaine J.D. \& Mikkola K. 1987: Lås-och-nyckel systemen i de inre genitalierna av Noctuidae (Lepidoptera) som taksonomiska kännetecken. [Lock-and-key systems in the inner genitalia of Noctuidae (Lepidoptera) as a taxonomic character.] Entomol. Meddelelser 55: 161-167 [in Swedish, with English abstr.].

Lafontaine J.D. \& Mikkola K. 2003: New species of Xanthia (Lepidoptera, Noctuidae) from North America. Can. Entomol. 135: 549-554.

LAFONTAINE J.D. \& Wood D.M. 1988: A zoogeographic analysis of the Noctuidae (Lepidoptera) of Beringia, and some inferences about past Beringian habitats. Mem. Entomol. Soc. Can. 144: 109-123.

Lafontaine J.D., Mikkola K., Kononenko V.S. \& Ahola M. 1998: Subgenus Pachnobia Guenée, In Lafontaine J.D.: Noctuoidea, Noctuidae, Noctuini. The Moths of America North of Mexico 27/3. E.W. Classey, London, pp. 139-165.

LAMUNYON C.W. 1997: Increased fecundity, as a function of multiple mating, in an arctiid moth, Utetheisa ornatrix. Ecol. Entomol. 22: 69-73.

Lederer G. 1941: Die Naturgeschichte der Tagfalter. II. Stuttgart, $186 \mathrm{pp}$.

LORKOVIC Z. 1952: L'accouplement artificiel chez les Lépidoptères et son application dans les recherches sur la fonction de l'appareil génital des insects. Physiol. Compar. Oecol. 3: 313-319.

MaKeE H. \& SaOur G. 2001: Factors influencing mating success, mating frequency and fecundity in Phthorimaea operculella (Lepidoptera: Gelechiidae). Environ. Entomol. 30: 31-36.

Marcondes C.P. \& AleXANDER B. 2003: Correlation of male genital filaments and female spermathecal ducts in the New World sand flies of the Lutzomyia intermedia species complex (Diptera: Psychodidae, Phlebotominae). Mem. Inst. Oswaldo Cruz 98: 611-613.

MAYR E. 1963: Animal Species and Evolution. Belknap, Cambridge, Mass., xiv +797 pp.

MiкKоLA K. 1992: Evidence for lock-and-key mechanisms in the internal genitalia of the Apamea moths (Lepidoptera, Noctuidae). Syst. Entomol. 17: 145-153.

MiKKola K. 1993: The lock-and-key mechanisms in the internal genitalia of the noctuid and geometrid moths (Lepidoptera) in relation to the speciation concepts. Folia Baeriana 6: 149-157.

MikKola K. 1994: Inferences about the function of genitalia in the genus Eupithecia, with description of a new organ (Lepidoptera, Geometridae). Nota Lepid. (Suppl. 5): 73-78.

Mikkola K. 1998: Revision of the genus Xylomoia Staudinger (Lepidoptera: Noctuidae), with descriptions of two new species. System. Entomol. 23: 173-186.

MiкKola K. 2007: The rise of eversion techniques in lepidopteran taxonomy (Insecta: Lepidoptera). SHILAP Revta Lepid. 35: $335-345$.
Mikkola K. \& Jalas I. 1977: Suomen perhoset. Yökköset 1. [Finnish Lepidoptera, Noctuidae 1.] Otava, Helsinki [in Finnish with English advice for non-Finnish readers].

MikKola K. \& Lafontaine J.D. 1986: A preliminary note on the taxonomy of the Apamea zeta complex, with the first report of A. zeta from Fennoscandia (Lepidoptera, Noctuidae). Notul. Entomol. 66: 91-95.

Mikkola K., Lafontaine J.D. \& Kononenko V.S. 1991: Zoogeography of the Holarctic species of the Noctuidae (Lepidoptera): importance of the Beringian refuge. Entomol. Fenn. 2: $157-173$

MiLLER J.S. 1988: External genitalic morphology and copulatory mechanism of Cyanotricha necyria (Felder) (Dioptidae). $J$. Lepid. Soc. 42: 103-115.

Mustelin T., Leuschner R., Mikkola K. \& Lafontaine J.D. 2000: Two new genera and thirteen new species of owlet moths (Lepidoptera: Noctuidae), mainly from Southern California. Proc. San Diego Soc. Nat. Hist. 36: 7-9.

Mutanen M. \& Kaitala A. 2006: Genital variation in a dimorphic moth Selenia tetralunaria (Lepidoptera, Geometridae). Biol. J. Linn. Soc. 87: 297-307.

Mutanen M., Kaitala A. \& MönkKöNen M. 2006: Genital variation within and between three closely related Euxoa moth species: testing the lock-and-key hypothesis. J. Zool. 268: 109-119.

NAumann C. 1987: Functional morphology of the external male and female genitalia in Zygaena Fabricius, 1775 (Lepidoptera: Zygaenidae). Entomol. Scand. 18: 213-219.

Ohno S., Hoshizaki S., Ishikawa Y., Tatsuki S. \& Akimoto S. 2003: Allometry of male genitalia in a lepidopteran species, Ostrinia latipennis (Lepidoptera: Crambidae). Appl. Entomol. Zool. 38: 313-319.

Osorio-Osorio R. \& Cibrián-Tovar J. 2000: Comportamiento reproductivo del barrenador de la caña de azúcar Diatraea considerata Heinrich (Lepidoptera, Pyralidae). Artíc. Agrocien. 34: 595-602.

Paterson H.E.H. 1985: The recognition concept of species. In Vrba E.S. (ed.): Species and Speciation. Transvaal Mus. Monogr. 4., Pretoria, pp. 21-29.

Pendergrast J.G. 1956: Studies on the reproductive organs of the Heteroptera with a consideration of their bearing on classification. Trans. R. Entomol. Soc. Lond. 109: 1-63.

Petersen W. 1904: Die Morphologie der Generationsorgane der Schmetterlinge. Mem. Acad. Imp. Sci. St Petersbourg VIII 16: $1-84$.

PriestaF R.C. 1974: Hybrid between Colias eurytheme and Colias harfordii (Pieridae) captured in California (Lep.). $J$. Lep. Soc. 28: 358.

Proshold F.I., LaChance L.E. \& Richard R.D. 1975: Sperm production and transfer by Heliothis virescens, H. subflexa and the sterile hybrid males. Anns Entomol. Soc. Am. 68: 31-34.

Rentz D. 1972: The lock and key as an isolating mechanism in katydids. Am. Sci. 60: 750-755.

REUTER O.M. 1880: Om anormala kopulationsförhållanden hos insekterna och i sammanhang därmed stående frågor. [About anomalous copulatory conditions in insects and questions arising thereby.] Öfvers. Finska VetenskSoc. Förh. 23: 1-30.

Rice W.R. \& HosterT E.E. 1993: Laboratory experiments on speciation: what have we learnt in 40 years? Evolution 47: $1637-1653$.

SADEK M.M. 2001: Polyandry in field-collected Spodoptera littoralis moths and laboratory assessment of the effects of male mating history. Entomol. Exp. Appl. 98: 165-172. 
SAnMartín I., Enghoff H. \& RonQuist F. 2001: Patterns of animal dispersal, vicariance and diversification in the Holarctic. Biol. J. Linn. Soc. 73: 345-390.

Scoble M.J. 1995: The Lepidoptera: Form, Function and Diversity. The Natural History Museum and Oxford University Press, Oxford, $404 \mathrm{pp}$

Shapiro A.M. \& Porter A.H. 1989: The lock-and-key hypothesis: evolutionary and biosystematic interpretation of insect genitalia. Annu. Rev. Entomol. 34: 231-245.

SiHVONEN P. 2007: Mating behaviour and copulation mechanisms in the genus Scopula (Geometridae: Sterrhinae). Nota Lepid. 30: 299-313.

Sinvonen P. \& Mikkola K. 2002: Taxonomical characters of Selidosema plumarium and S. brunnearium (Lepidoptera: Geometridae: Ennominae) and the function of the internal genitalia during copulation. Entomol. Fenn. 13: 13-19.

Simmon A.M. \& Mart O.G. JR. 1992: Mating by the fall armyworm (Lepidoptera: Noctuidae): freguency, duration, and effect of temperature. Environ. Entomol. 21: 371-375.

SIMS S.R. 1979: Aspects of mating frequency and reproductive maturity in Papilio zelicaon. Am. Midland Nat. 102: 36-50.

Song S., Dey D. \& Holsinger K.E. 2006: Differentiation among populations with migration, mutation, and drift: implications for genetic inference. Evolution 60: 1-12.

Sota T. \& Kuвота K. 1998: Genital lock-and-key as a selective agent against hybridization. Evolution 52: 1507-1513.

SudENDEY F. 2003: Fremdkopula zwischen Distelfalter Cynthia cardui (Linnaeus, 1758) und dem Grossen Ochsenauge Maniola jurtina (Linnaeus, 1758) (Lepidoptera, Rhopalocera). Atalanta 34: 384.

Svensson M.G.E., Marling E. \& LöfQvist J. 1998: Mating behavior and reproductive potential in the turnip moth Agrotis segetum (Lepidoptera: Noctuidae). J. Insect Behav. 11: 343-359.

SvÄRD L. \& MCNEIL J.N. 1994: Female benefit, male risk: polyandry in the true armyworm, Pseudaletia unipuncta. Behav. Ecol. Sociobiol. 35: 319-326.

SzIRÁKI G. 2002: Contribution to knowledge of female internal genitalia of Neuroptera. Acta Zool. Acad. Sci. Hung. (Suppl. 2) 48: 341-349.

TADLER Y. 1999: Selection of a conspicuous male genital trait in the seedbug Lygaeus simulans. Proc. R. Soc. Lond. 266: 1773-1777.

TAKAMI Y. 2003: Experimental analysis of the effect of genital morphology on insemination success in the ground beetle Carabus insulicola (Coleoptera Carabidae). Ethol. Ecol. Evol. 15: $51-61$

TAYLOR O.R. JR. 1972: Random vs. non-random mating in sulfur butterflies, Colias eurytheme and Colias philodice (Lepidoptera: Pieridae). Evolution 26: 344-356.

TEMPLETON A.R. 1989: The meaning of species and speciation: A genetic perspective. In Otte D. \& Endler J.A. (eds): Speciation and its Consequences. Sinauer, Sunderland, Mass., pp. $3-27$

Thornhill R. \& Alcock J. 1983: The Evolution of Insect Mating Systems. Harvard University Press, Cambridge, Mass., $547 \mathrm{pp}$.
Torres-Vila L.M., Rodriguez-Molina M.C., Gragera J. \& Bielza-Lino P. 2001: Polyandry in Lepidoptera: a heritable trait in Spodoptera exigua Hübner. Heredity 86: 177-183.

Troubridge J.T. \& FitzPatrick S.M. 1993: A revision of the North American Operophtera (Lepidoptera, Geometridae). Can. Entomol. 125: 379-397.

Turgeon J., Stocks R., Thum R.A., Brown J.M. \& McPeek M.A. 2005: Simultaneous quaternary radiations of three damselfly clades across the Holarctic. Am. Nat. 165: 78-107.

UEdA K. \& Saigusa T. 1982: On the copulation mechanism of Eligma narcissus (Cramer) (Lepidoptera, Noctuidae). Bull. Kitakyushu Mus. Nat. Hist. 4: 15-22.

Usami T., Yokoyama J., Kubota K. \& Kawata M. 2006: Genital lock-and-key system and premating isolation by mate preference in carabid beetles (Carabus subgenus Ohomopterus). Biol. J. Linn. Soc. 87: 145-154.

VAHED K. 1998: The function of nuptial feeding in insects: a review of empirical studies. Biol. Rev. 73: 43-78.

VÄLIMÄKI P. \& KaItala A. 2007: Life history tradeoffs in relation to the degree of polyandry and developmental pathway in Pieris napi (Lepidoptera, Pieridae). Oikos 116: 1569-1580.

VARGA Z. 1998: Sibling species and species groups in the genus Chersotis Boisduval, 1840 (Lepidoptera, Noctuidae: Noctuinae) with description of two new species. Acta Zool. Acad. Sci. Hungar. 44: 341-372.

VARga Z. \& Guylai P. 1999: Taxonomy of the genus Ctenoceratoda Varga, 1992 (Lepidoptera, Noctuidae) with the description of seven new species. Acta Zool. Acad. Sci. Hungar. 45: 169-197.

VARGa Z., Ronkay L. \& HACKer H. 1990: Revision of the genus Bryopolia Boursin, 1954 (Lepidoptera, Noctuidae). Esperiana 1: $427-470$.

WANG B. \& PORTER A.H. 2004: An AFLP-based interspecific linkage map of sympatric, hybridizing Colias butterflies. Genetics 168: 215-225.

Wedell N., Wiklund C. \& Cook P.A. 2002: Monandry and polyandry as alternative lifestyles in a butterfly. Behav. Ecol. 13: $450-455$.

WickMAn P.-O. 1985: [Observation of a mating between the two satyrid butterflies Coenonympha arcania (male) and Aphantopus hyperantus (female)]. Entomol. Tidskr. 106: 45 [in Swedish].

WIEMERS M. 1987: Beitrag zur artfremden Freilandpaarung. Eine Freilandkopula zwischen Mellicta (Lep.: Nymphalidae) und Amata (Lep.: Ctenuchidae) sowie eine weitere ZygaenenHybridkopula (Lep.: Zygaenidae). Entomol. Ztg 97: 27-30.

Wiklund C., Karlsson B. \& Leimar O. 2001: Sexual conflict and cooperation in butterfly reproduction: a comparative study of polyandry and female fitness. Proc. R. Soc. Lond. (B) 268: $1661-1667$.

WiKLund C., GotThard K. \& Nylin S. 2003: Mating system and the evolution of sex-specific mortality rates in two nymphalid butterflies. Proc. R. Soc. Lond. (B) 270: 1823-1828.

YelA J.L. 2002: The internal genitalia as a taxonomic tool: description of the relict endemic moth, Coranarta restricta $\mathrm{sp.}$ $\mathrm{n}$., from the Iberian Peninsula (Lepidoptera: Noctuidae: Hadeninae). Entomol. Fenn. 13: 1-12.

Received November 15, 2006; revised and accepted June 7, 2007 